\title{
Potential of Hazardous Wastes Encapsulation in Concrete Compound Combination with Coal Ash and Quarry Fines Additives
}

Roy Nir Lieberman*1,2 , Yaakov Anker ${ }^{3}$, Oriol Font ${ }^{* 4}$, Xavier Querol ${ }^{4}$, Yitzhak Mastai ${ }^{2}$, Yaniv Knop ${ }^{5}$, Haim Cohen ${ }^{* 1,6}$

1. Biological Chemistry Department, Ariel University Samaria, Ariel, 40700 Israel.

2. Department of Chemistry and the Institute of Nanotechnology, Bar-Ilan University, Ramat-Gan, Israel.

3. Samaria and the Jordan Rift regional R\& D Center, Ariel, Israel.

4. Institute of Environmental Assessment and Water Research (IDAEA), Consejo Superior de Investigaciones Cientificas (CSIC), Barcelona, Spain

5. Department of Chemical Engineering, Ariel University Samaria, Ariel,40700 Israel.

6. Chemistry Department, Ben-Gurion University of the Negev, Beer-Sheva, Israel.

*Co-responding authors: Roy Nir Lieberman: roynl@ariel.ac.il, 5dk32nl@gmail.com,roy.nir@idaea.csic.es Oriol Font: $\quad$ oriol.font@idaea.csic.es Haim Cohen: $\quad$ hcohen@ariel.ac.il

Number of pages in manuscript: 10

Number of tables in the manuscript: 4

Number of Figures: 3

Number of SI figures: 4 (S1-S4)

Supporting information for this article includes additional figures: Map of Israel and the Palestinian Authority (Figure S1), XRD analysis of quarry sludges (Figure S2), SEM image of the Ettringite/Thaumasite formation (Figure S3), and graphs of concrete strength and ion penetration tests (Figure S4). 
Figure S1: Israel and the West Bank map

\section{ISRAEL WITH THE \\ WEST BANK, \\ GAZA STRIP, AND GOLAN HEIGHTS}

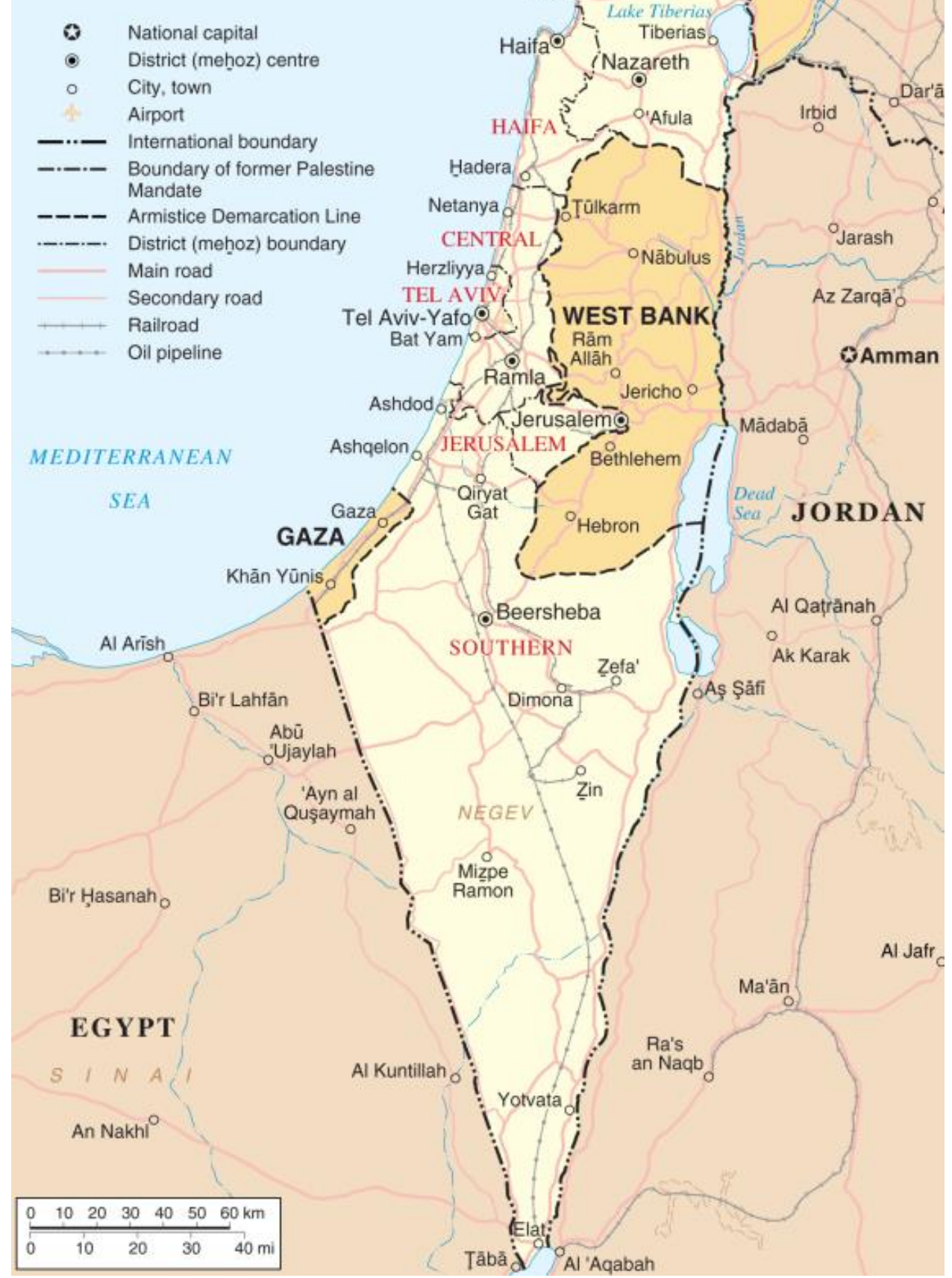

Picture taken from: http://mapsof.net/map/israel-west-bank-gaza-strip-and-golan-heights 
Figure S2: XRD analysis of dried quarry sludge

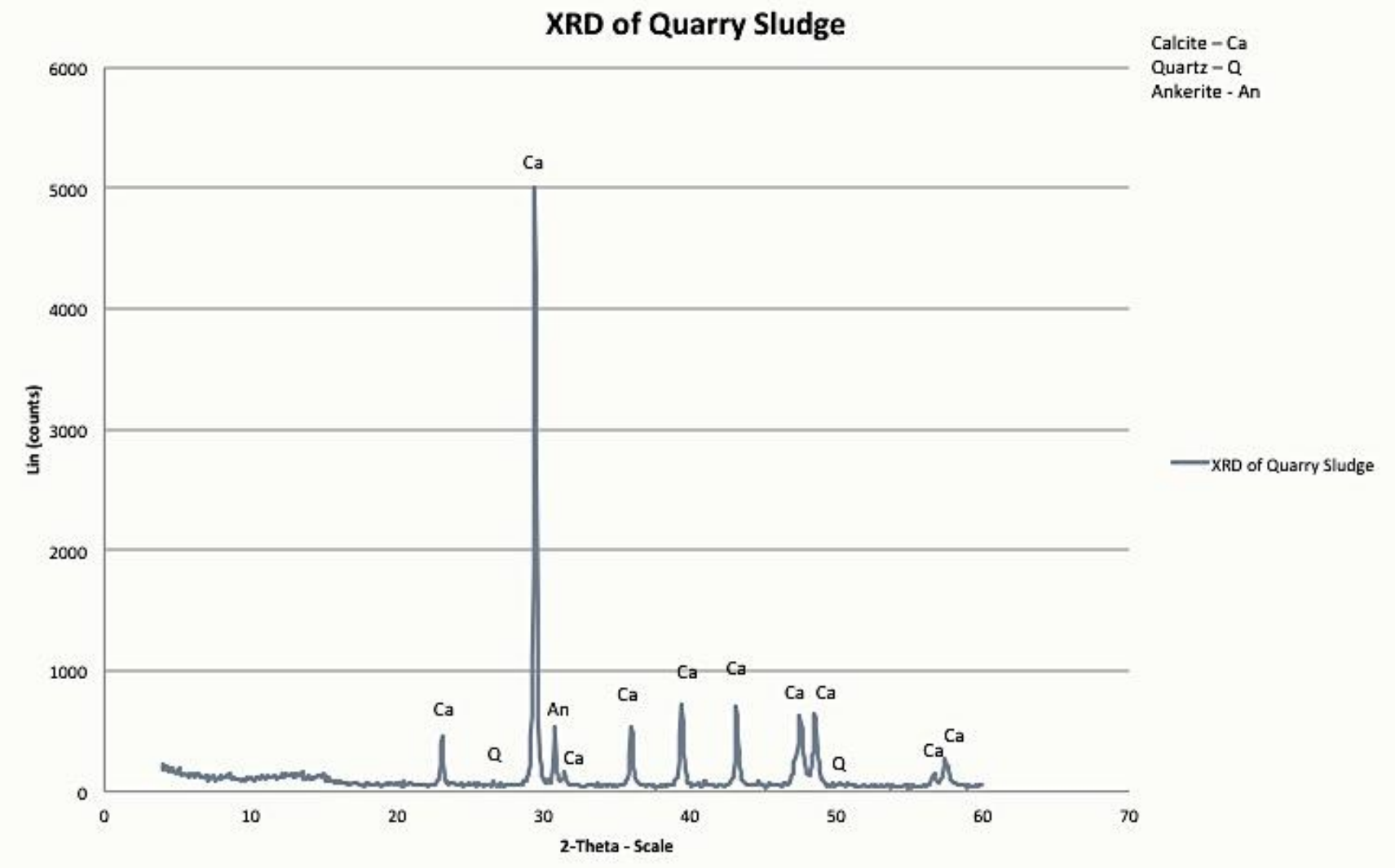


Figure S3: Ettringite/Thaumasite particles mixture as capture after South African fly ash + contact with ultra pure deionized water

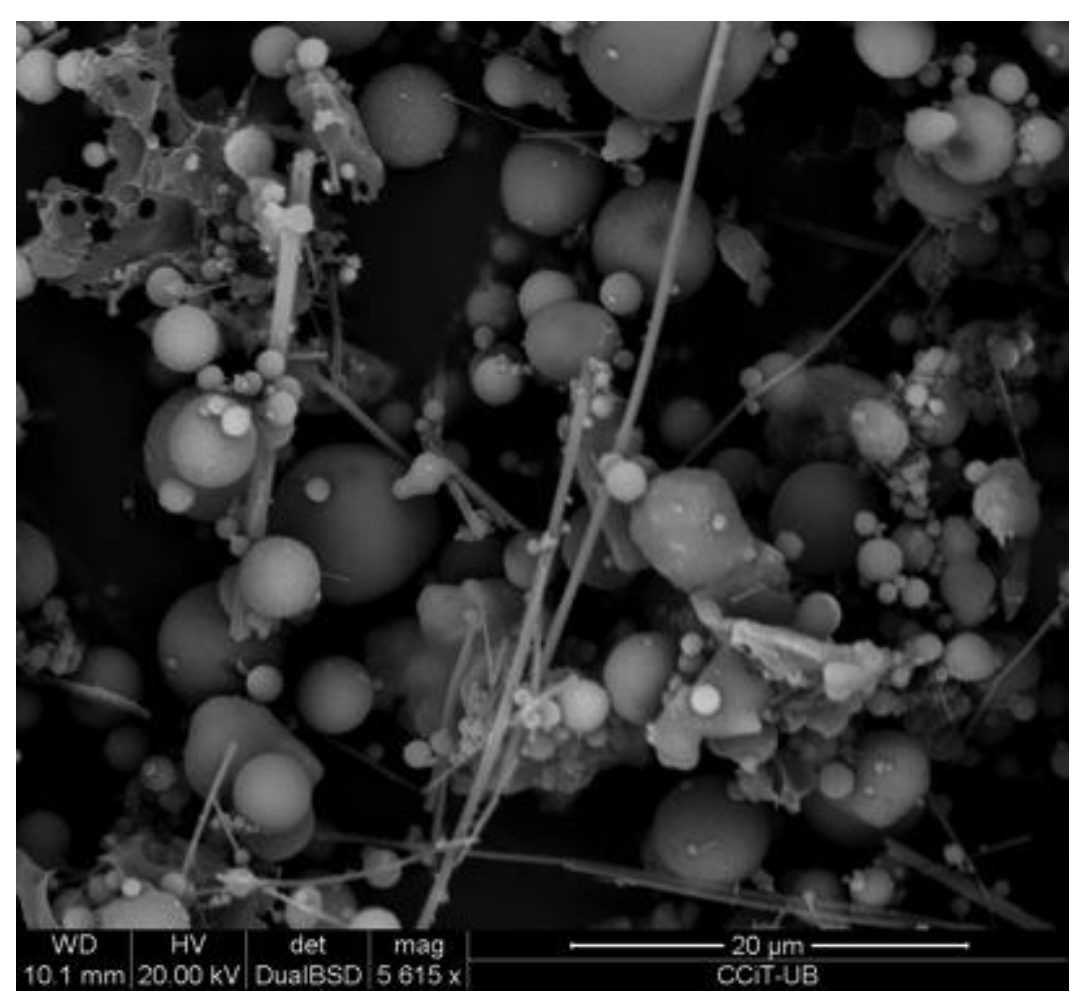


Figure S4: A - The compressive strengths after 28 and 90 days of the concrete with 50 and $100 \mathrm{~kg} / \mathrm{m}^{3}$ of aggregate product, the ratio between the compressive strength of the concrete mixes with aggregate product, to the strength of the concrete mix without aggregate product is presented.

B - The ion penetration in the concrete with 50 and $100 \mathrm{~kg} / \mathrm{m}^{3}$ aggregate product compared to concrete reference, AP free
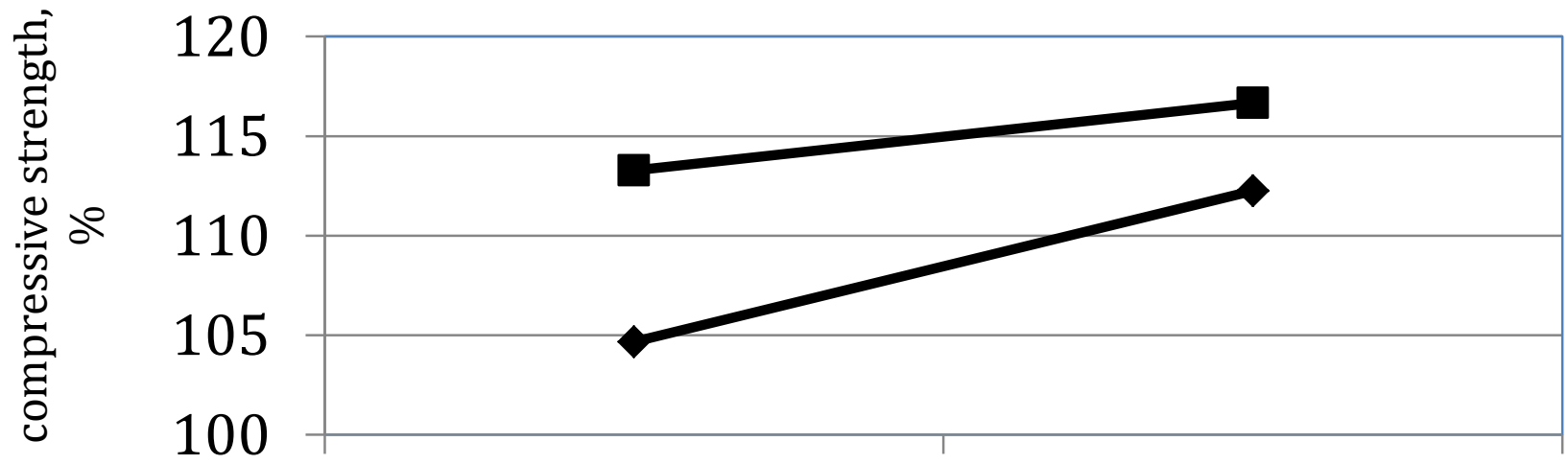

A

50

100

$\rightarrow 28$ days

FA/QS content, $\mathrm{kg} / \mathrm{m}^{3}$ concrete

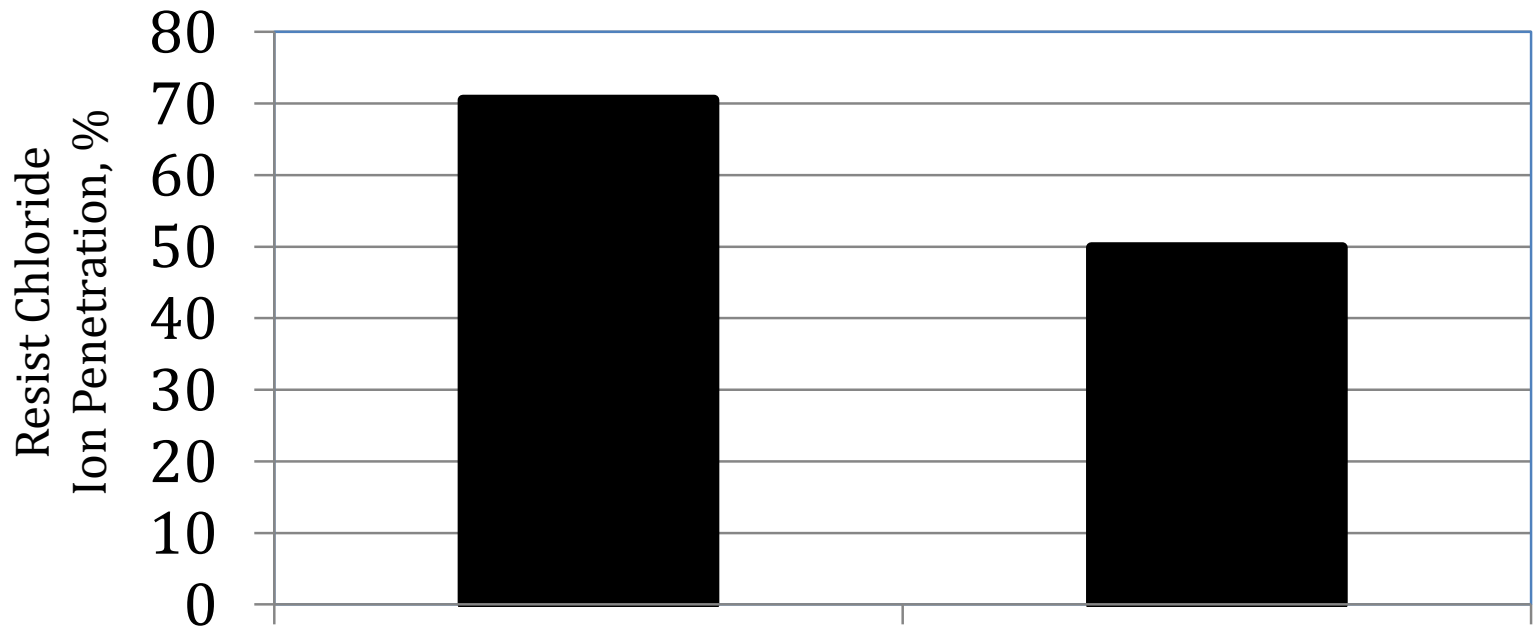

B

50

100

FA/QS content, $\mathrm{kg} / \mathrm{m}^{3}$ concrete 